\title{
Manifestações cutâneas corroboradas à infecção por SARS-Cov-2: uma revisão integrativa de literatura
}

\author{
Skin manifestations corroborated by SARS-Cov-2 infection: an integrative literature review \\ Manifestaciones cutáneas corroboradas por la infección por SARS-Cov-2: una revisión integradora \\ de la literatura
}

Recebido: 15/09/2021 | Revisado: 19/09/2021 | Aceito: 19/09/2021 | Publicado: 20/09/2021

Iuri Pimenta Oliveira

ORCID: https://orcid.org/0000-0002-9004-1513 Centro Universitário de Patos de Minas, Brasil E-mail: iuripimenta@unipam.edu.br

Bárbara Queiroz de Figueiredo ORCID: https://orcid.org/0000-0003-1630-4597 Centro Universitário de Patos de Minas, Brasil E-mail: barbarafigueiredo@unipam.edu.br

Rúbia Carla Oliveira

ORCID: https://orcid.org/0000-0002-7162-3497

Centro Universitário de Patos de Minas, Brasil E-mail: rubiacoliveira@unipam.edu.br

\begin{abstract}
Resumo
Introdução: Um número crescente de literaturas sobre as manifestações cutâneas de pacientes com Covid-19 foi relatado recentemente, sugerindo que as lesões cutâneas poderiam ser potenciais características clínicas da doença, principalmente manchas vermelhas nas mãos, bolhas no tronco e urticária com coceira. Em alguns pacientes acometidos pela doença, também foram observadas manchas vermelhas de coceira na pele, associadas à inflamação da pele. Objetivo: investigar a distribuição, os tipos e as manifestações cutâneas mais prevalentes entre pacientes com Covid-19 com base em relatos de casos, séries de casos e estudos de prevalência em todo o mundo. Metodologia: Trata-se de uma pesquisa descritiva do tipo revisão integrativa da literatura. A pesquisa foi realizada através do acesso online nas bases de dados National Library of Medicine (PubMed MEDLINE), Scientific Electronic Library Online (Scielo), Cochrane Database of Systematic Reviews (CDSR), Google Scholar, Biblioteca Virtual em Saúde (BVS) e EBSCO Information Services, no mês de setembro de 2021. Resultados e discussão: Por mais raras que possam ser, as lesões na pele são notadas alguns dias antes dos principais sintomas, como tosse, febre e falta de ar. Geralmente, as lesões se assemelham a outras doenças dermatológicas. Vermelhidão, coceira intensa, bolhas, vergões, caroços e manchas podem atingir diversas regiões do corpo como a pele, unhas e até mesmo mucosas. Conclusão: Apesar da observação de manifestações cutâneas em pacientes com Covid-19, pesquisadores ainda buscam respostas para a questão de saber se essas apresentações cutâneas estão diretamente relacionadas ao próprio vírus ou são complicações da infecção.
\end{abstract}

Palavras-chave: Covid-19; SARS-CoV-2; Exantema: Manifestação cutânea; Rash cutâneo.

\begin{abstract}
Introduction: A growing body of literature on the cutaneous manifestations of patients with Covid-19 has been reported recently, suggesting that cutaneous lesions could be potential clinical features of the disease, particularly red spots on the hands, blisters on the trunk, and itchy urticaria. In some patients affected by the disease, red itchy patches of skin associated with skin inflammation were also observed. Objective: to investigate the most prevalent distribution, types and skin manifestations among patients with Covid-19 based on case reports, case series and prevalence studies worldwide. Methodology: This is a descriptive research of the integrative literature review type. The search was carried out through online access in the National Library of Medicine (PubMed MEDLINE), Scientific Electronic Library Online (Scielo), Cochrane Database of Systematic Reviews (CDSR), Google Scholar, Virtual Health Library (BVS) and EBSCO databases Information Services, September 2021. Results and Discussion: As rare as they may be, skin lesions are noticed a few days before major symptoms such as cough, fever, and shortness of breath. Generally, the lesions resemble other skin diseases. Redness, intense itching, blisters, welts, lumps and spots can reach different parts of the body such as the skin, nails and even mucous membranes. Conclusion: Despite the observation of cutaneous manifestations in patients with Covid-19, researchers are still seeking answers to the question of whether these cutaneous presentations are directly related to the virus itself or are complications of the infection.
\end{abstract}

Keywords: Covid-19; SARS-CoV-2; Exanthema: Skin manifestation; Skin rash. 


\begin{abstract}
Resumen
Introducción: Recientemente se ha informado de un creciente cuerpo de literatura sobre las manifestaciones cutáneas de pacientes con Covid-19, lo que sugiere que las lesiones cutáneas podrían ser características clínicas potenciales de la enfermedad, particularmente manchas rojas en las manos, ampollas en el tronco y urticaria con picazón. . En algunos pacientes afectados por la enfermedad, también se observaron parches de piel rojos que pican asociados con la inflamación de la piel. Objetivo: investigar la distribución, los tipos y las manifestaciones cutáneas más prevalentes entre los pacientes con Covid-19 basándose en informes de casos, series de casos y estudios de prevalencia en todo el mundo. Metodología: Se trata de una investigación descriptiva del tipo revisión integradora de la literatura. La investigación se realizó a través del acceso en línea en la Biblioteca Nacional de Medicina (PubMed MEDLINE), Scientific Electronic Library Online (Scielo), Cochrane Database of Systematic Reviews (CDSR), Google Scholar, Virtual Health Library (BVS) y bases de datos EBSCO Information Services. , Septiembre de 2021. Resultados y discusión: por muy raras que sean, las lesiones cutáneas se notan unos días antes de los síntomas importantes como tos, fiebre y dificultad para respirar. Generalmente, las lesiones se parecen a otras enfermedades de la piel. El enrojecimiento, el picor intenso, las ampollas, las ronchas, los bultos y las manchas pueden llegar a distintas partes del cuerpo como la piel, las uñas e incluso las mucosas. Conclusión: A pesar de la observación de manifestaciones cutáneas en pacientes con Covid-19, los investigadores todavía están buscando respuestas a la pregunta de si estas presentaciones cutáneas están directamente relacionadas con el virus en sí o son complicaciones de la infección.
\end{abstract}

Palabras clave: Covid-19; SARS-CoV-2; Exantema: Manifestación cutánea; Erupción cutanea.

\title{
1. Introdução
}

Em dezembro de 2019, um novo coronavírus, a síndrome respiratória aguda grave coronavírus-2 (SARS-CoV-2), foi relatado pela primeira vez em Wuhan, China, como um agente etiológico que causa uma nova doença respiratória infecciosa, que se espalhou rapidamente em todo o mundo através da transmissão entre humanos e, em março de 2020 , a Covid-19 foi declarada como uma emergência pandêmica pela Organização Mundial da Saúde (OMS). Desse modo, as principais manifestações clínicas relatadas da doença foram febre, tosse, fadiga, produção de expectoração, dispneia e dores musculares, bem como diarreia, deficiências olfativas e gustativas causadas por Covid-19 também foram relatadas, mas menos comuns. Outrossim, um número crescente de literaturas sobre as manifestações cutâneas de pacientes com Covid-19 foi relatado recentemente, sugerindo que as lesões cutâneas poderiam ser potenciais características clínicas da doença, principalmente manchas vermelhas nas mãos, bolhas no tronco e urticária com coceira. Em alguns pacientes acometidos pela doença, também foram observadas manchas vermelhas de coceira na pele, associadas à inflamação da pele. Essas lesões afetam as mãos e os pés e podem parecer bolhas pequenas, inchadas e que coçam (Perna et al. 2020).

Vários pontos de vista sobre os mecanismos que induzem a erupção cutânea em pacientes com Covid-19 têm sido propostos, como: se o vírus pode infectar através de uma ferida aberta na pele; se as manifestações cutâneas estavam relacionadas às respostas imunológicas ou se as manifestações cutâneas foram causadas por um novo medicamento prescrito. Dado que a enzima conversora de angiotensina 2 (ECA2) é um receptor funcional crucial do SARS-CoV-2, a exploração da expressão da ECA2 nos tecidos cutâneos pode facilitar o esclarecimento dos mecanismos envolvidos nas manifestações cutâneas do Covid-19 (Marzano et al. 2020).. Assim, o presente estudo teve como objetivo investigar a distribuição, os tipos e as manifestações cutâneas mais prevalentes entre pacientes com Covid-19 com base em relatos de casos, séries de casos e estudos de prevalência em todo o mundo.

\section{Metodologia}

Trata-se de uma pesquisa descritiva do tipo revisão integrativa da literatura, que buscou evidenciar as manifestações cutâneas associadas à infecção por SARS-CoV-2. A pesquisa foi realizada através do acesso online nas bases de dados National Library of Medicine (PubMed MEDLINE), Scientific Electronic Library Online (Scielo), Cochrane Database of Systematic Reviews (CDSR), Google Scholar, Biblioteca Virtual em Saúde (BVS) e EBSCO Information Services, no mês de 
setembro de 2021. Para a busca das obras foram utilizadas as palavras-chaves presentes nos descritores em Ciências da Saúde (DeCS): em inglês: "Covid-19", "SARS-CoV-2", "skin lesion", "skin", "rash", "dermatology", em espanhol: "Covid-19", "SARS-CoV-2", "lesión cutánea", "piel", "erupción", "dermatología" e em português: "Covid-19", "SARS-CoV-2", "lesão cutânea", "pele", "exantema", "dermatologia"

Como critérios de inclusão, foram considerados artigos originais, que abordassem o tema pesquisado e permitissem acesso integral ao conteúdo do estudo, publicados no período de 2020 a 2021, em inglês, espanhol e português. O critério de exclusão foi imposto naqueles trabalhos que não estavam em inglês, português e espanhol que não tinham passado por processo de Peer-View e que não abordassem as manifestações cutâneas sob espectro do acometimento por Covid-19. A estratégia de seleção dos artigos seguiu as seguintes etapas: busca nas bases de dados selecionadas; leitura dos títulos de todos os artigos encontrados e exclusão daqueles que não abordavam o assunto; leitura crítica dos resumos dos artigos e leitura na íntegra dos artigos selecionados nas etapas anteriores. Assim, totalizaram-se 21 artigos científicos para a revisão integrativa da literatura, com os descritores apresentados acima.

\section{Resultados e Discussão}

Uma das questões mais importantes que pode ser aprendida no futuro é a associação de Covid-19 com outras infecções. Semelhante a outros vírus de RNA, a infecção por SARS-CoV-2 pode estar associada a manifestações cutâneas (Kaur et al. 2020). Recentemente, evidências de várias manifestações cutâneas em pacientes com Covid-19 tornaram a doença um grande desafio no mundo. Nesse sentido, o número de relatos de manifestações cutâneas em nesses pacientes está constantemente aumentando em todo o mundo, especialmente em países europeus (Avellana et al. 2020).

Sob esse cenário. pesquisa de Perna et al. (2021) constatou que, dentre todos os pacientes analisados, infectados por Covid-19, as lesões cutâneas foram relatadas em apenas 957 (60,1\%) casos. Em 13 (1,3\%) pacientes, foi observada erupção cutânea inespecífica. Em 120 (12,5\%) pacientes foi relatada a presença de lesões vesiculares. Em 86 (9\%) pacientes, lesões cutâneas eritematosas e urticária foram documentadas. Além disso, livedo reticular foi observado em 35 (3,6\%) casos. Lesões cutâneas maculopapulares foram descritas em 218 (22,8\%) pacientes. O padrão de lesão cutânea prevalente relatado foi lesão de frieira, observada em 460 pacientes (48\%). Quanto à localização das lesões cutâneas, 456 (47,6\%) pacientes apresentavam lesões nas mãos (149) ou nos pés (307), 370 (38,7\%) pacientes apresentavam lesões no tórax ou nas costas, 314 (32,8\%) pacientes apresentavam lesões nos membros (inferior e superior) e $20(2,1 \%)$ pacientes apresentavam lesões faciais ou cervicais. Lesões nas mãos e pés eram lesões prevalentemente frias (98\%). Duzentos e sessenta e um pacientes (27,3\%) apresentavam lesões cutâneas com prurido, enquanto 76 (7,9\%) pacientes apresentavam lesões cutâneas dolorosas.

Sob essa perspectiva, segundo Sachdeva et al. (2020), a manifestação cutânea mais comum da Covid-19 também foi exantema maculopapular (morbiliforme), presente em 36,1\% dos pacientes. As outras manifestações cutâneas incluíram: erupção cutânea papulovesicular (34,7\%), urticária (9,7\%), pápulas vermelhas acrais dolorosas $(15,3 \%)$ dos pacientes, lesões livedo reticular $(2,8 \%)$ e petéquias $(1,4 \%$,). A maioria das lesões localizava-se no tronco (66,7\%), no entanto, $19,4 \%$ dos pacientes apresentaram manifestações cutâneas nas mãos e pés. O desenvolvimento de lesões cutâneas ocorreu antes do início dos sintomas respiratórios ou do diagnóstico de Covid-19 em 12,5\% dos pacientes, e as lesões cicatrizaram espontaneamente em todos os pacientes em 10 dias. A maioria dos estudos não relatou correlação entre a gravidade do Covid-19 e as lesões cutâneas.

Estudo de Recalcati et al. (2020) relatou lesões cutâneas peculiares, semelhantes a perniose, em pacientes acometidos por Covid-19, que consistiam em erupção acral de pápula e máculas eritemato-violàcceas, com possíveis evoluções bolhosas ou edemas a dígito-pressão. No entanto, nenhum sintoma sistêmico foi relatado, exceto prurido leve em três casos, conforme ilustrado pela Figura 1. Aliado a isso, resultados laboratoriais de rotina eram normais, incluindo hemograma completo, 
proteína C reativa, desidrogenase láctica e dímero D, bem como sorologia descartou infecção por vírus Epstein-Barr, citomegalovírus, Coxsackie e parvovírus B19. Além disso, biópsias cutâneas realizadas sugeriram infiltrado linfoide difuso e denso da derme superficial e profunda, sinais de ativação endotelial e hipoderme com padrão perivascular superficial, bem como foi observada a expressão de ACE2 na pele, especialmente nos queratinócitos.

Figura 1: Imagens clínicas: (a) Pápulas violáceas e edema digital nos pés de uma menina de 14 anos; uma pequena bolha sobreposta é visível no dedão do pé. (b) máculas roxas no pé direito de uma menina de 18 anos. (c) máculas eritematosas na mão direita de uma menina de 14 anos. Lesões alvos estão presentes. (d) lesões-alvos nos cotovelos de um menino de 11 anos.

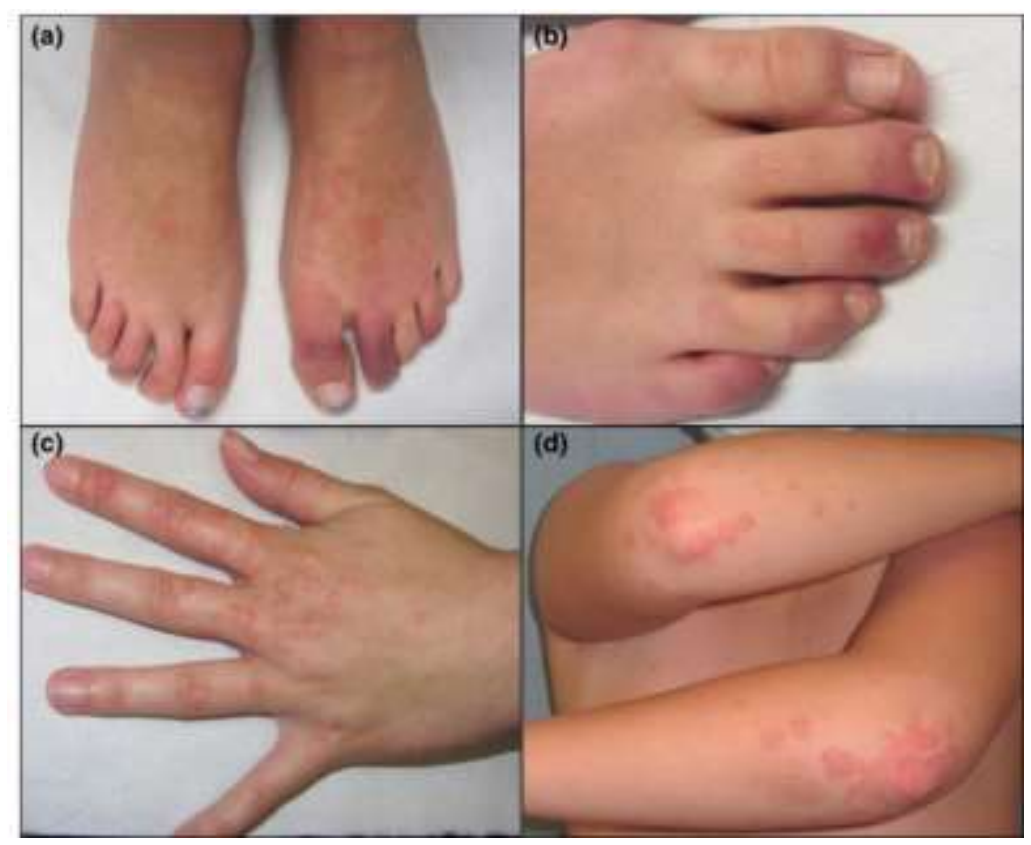

Fonte: Recalcati et al. (2020).

Sob essa perspectiva, estudo de 22 casos clínicos, de Marzano et al. (2020), concluiu que o tempo médio de latência dos sintomas sistêmicos ao exantema foi de 3 dias (variação de 2 a 12 dias) e a duração média das manifestações cutâneas foi de 8 dias (variação entre 4 e 15 dias). Além disso, as lesões eram dispersas na maioria dos pacientes e difusas em 6 pacientes e a predominância de vesículas foi observada em 12 pacientes, e nenhuma variação na apresentação papulovesicular foi observada, conforme ilustrado pela Figura 2. Outrossim, o tronco sempre esteve envolvido, em alguns casos em associação com os membros e nenhum envolvimento facial ou mucoso foi avaliado. Também, prurido leve, foi relatado em 9 pacientes. Além disso, em todos os pacientes submetidos à biópsia de pele, os achados histológicos foram consistentes com infecção viral. 
Figura 2: Exantema papulovesicular no tronco em 4 pacientes com Covid-19. (ABC) em 3 pacientes, é observada predominância de pápulas. (D): Em outro paciente apresentando principalmente vesículas, a resolução do exantema com crostas é evidente; E: hiperceratose de onda de cesta; epiderme ligeiramente atrófica; e degeneração vacuolar da camada basal com queratinócitos multinucleados, hipercromáticos e células disceratóticas. Ao padrão histológico, observar a ausência de infiltrado inflamatório (F) Imagem de close-up com epiderme atrófica, alteração vacuolar com queratinócitos desorganizados sem maturação ordenada e queratinócitos aumentados e multinucleados com células disceratóticas (apoptóticas)
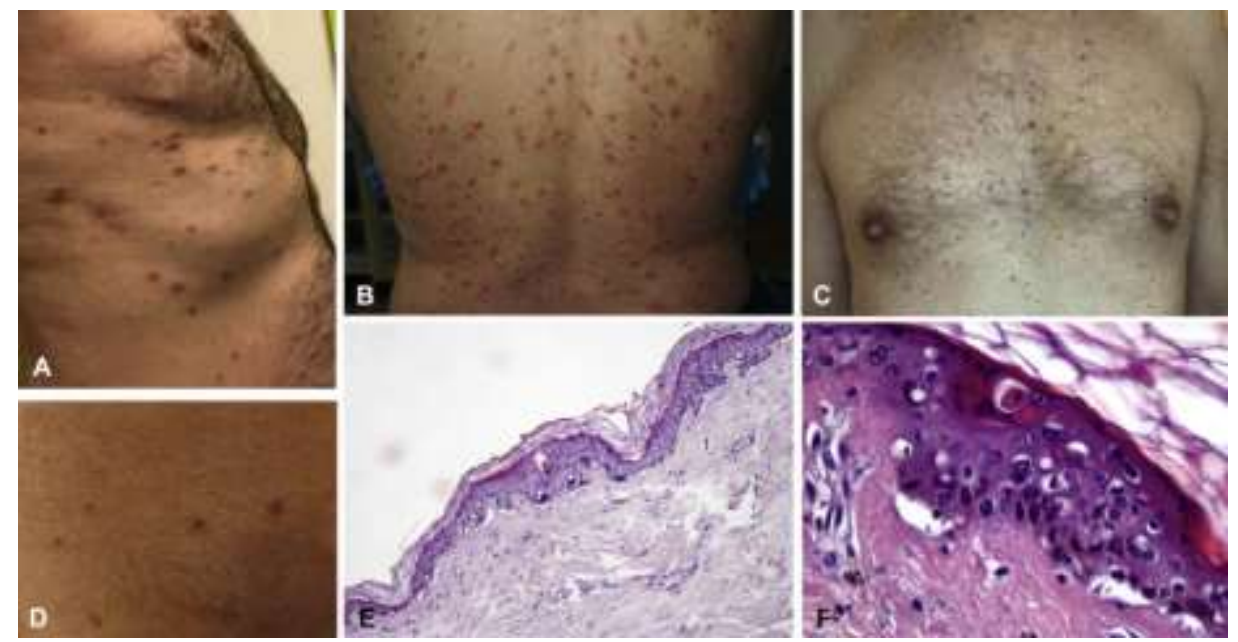

Fonte: Marzano et al. (2020).

Já estudo de Askin et al. (2020), por meio de metanálise, evidenciou os seguintes padrões clínicos em 52 pacientes: erupção cutânea escamosa eritematosa em 32,7\% dos casos, sendo a maioria das lesões observada nas mãos (Figura 3) (Suchonwanit et al. 2020); erupção cutânea maculopapular em $23 \%$ dos casos, sendo que a maioria das lesões foi vista no tronco (uma foi vista nas extremidades e uma foi vista apenas na parte superior do tronco), e uma das lesões do tronco era semelhante a pitiríase rósea (Figura 4) e lesões urticariformes 13,5\% dos casos, distribuído principalmente em todo o corpo (Kay et al. 2020); erupção cutânea purpúrica petequial em extremidades distais em 7,7\% dos casos e petéquias, sendo que um paciente apresentou erupção purpúrica generalizada e petequial; níveis de plaquetas e os testes de coagulação dos pacientes eram normais; necrose em 7,7\% dos casos e menos comumente observada em um paciente na região maxilar, enquanto a maioria nas áreas de compressão, como o sacro (Tang et al. 2020). Além disso, enantema e estomatite apthous foram presentes em 5,8\% dos casos e eritemas foram observados na mucosa oral. Em um paciente, tanto enantema quanto estomatite aftosa foram vistos juntos, enquanto o outro paciente apresentava lesão aftosa em apenas um lado da língua. Outrossim, erupção cutânea vesicular foi vista em 5,8\% dos casos, sendo dois deles unilaterais e monomórficos na parte superior do tronco. Além disso, cianose foi observada em áreas acrais em um paciente (Figura 5), prurido em 1,9\% dos casos. Acredita-se que o sintoma esteja relacionado à vancomicina, mas a confirmação clínico-patológica não pode ser feita (Tammaro et al. 2020). 
Research, Society and Development, v. 10, n. 12, e270101220625, 2021

(CC BY 4.0) | ISSN 2525-3409 | DOI: http://dx.doi.org/10.33448/rsd-v10i12.20625

Figura 3: Dermatite de contato nas mãos.

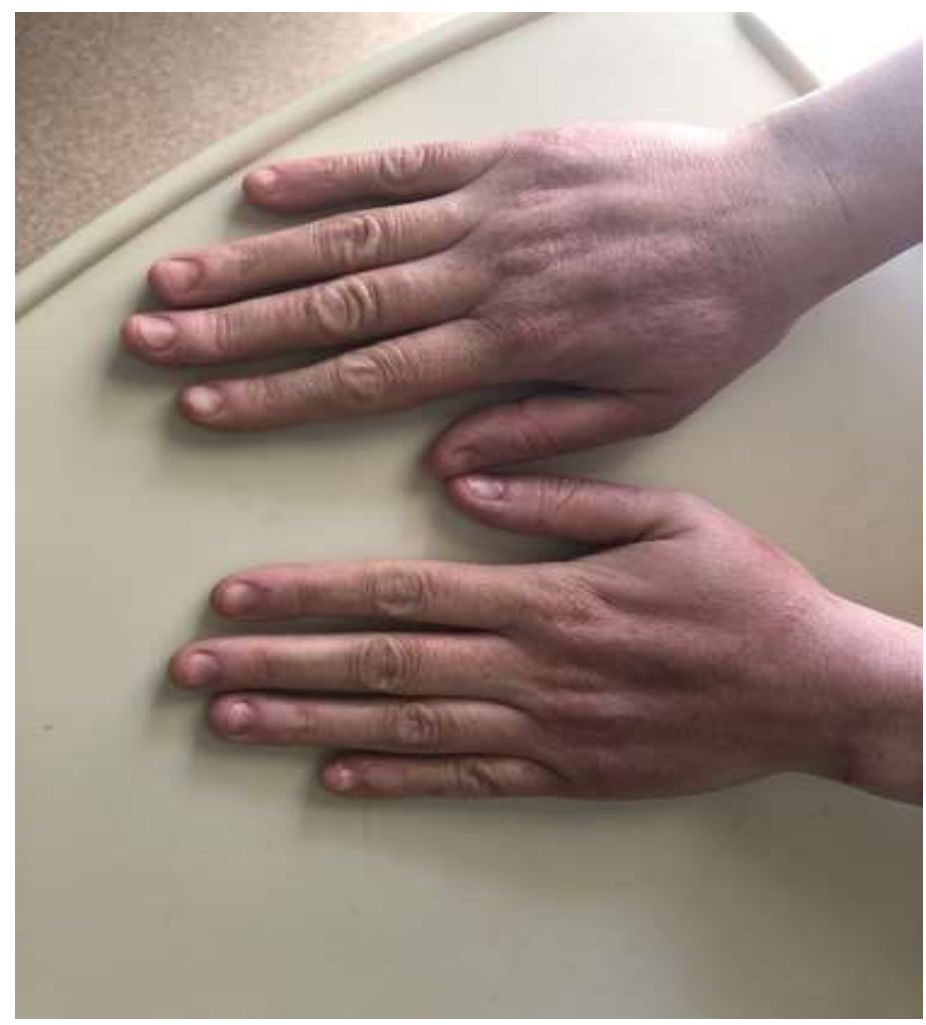

Fonte: Suchonwanit et al. (2020).

Figura 4: Erupção macular no tronco.

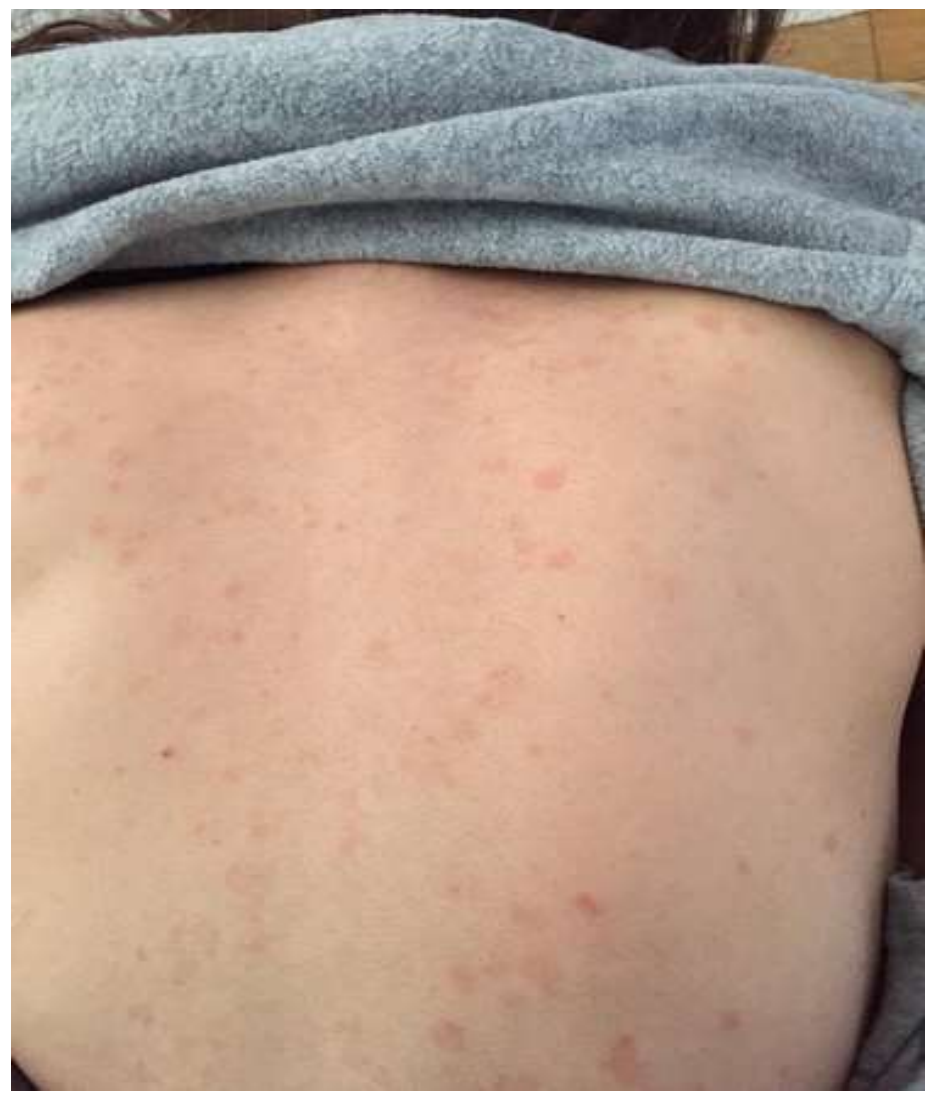

Font: Kay et al. (2020). 
Figura 5: Cianose nas áreas acrais.

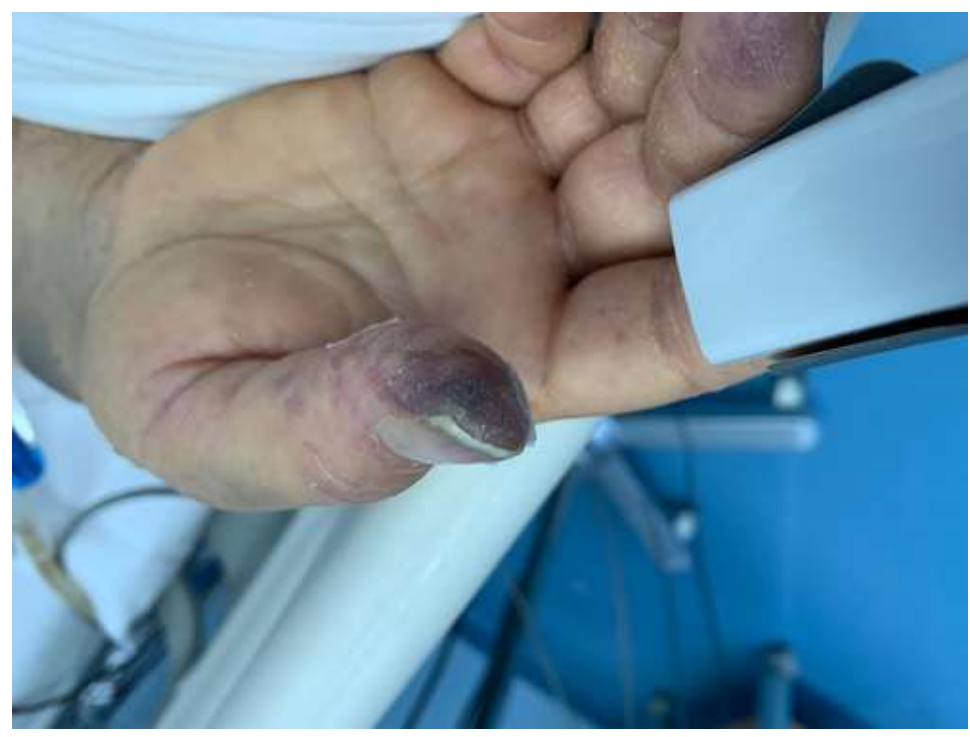

Fonte: Tammaro et al. (2020).

Os sintomas clínicos também foram verificados em pacientes com Covid-19 e manifestações cutâneas. Dentre eles, Sameni et al. (2020) pontua febre, tosse, dispneia, diarreia e cefaleia. Além disso, dos 14 tipos de comorbidades registradas nos estudos, diabetes, obesidade, hipertensão e insuficiência renal crônica foram as comorbidades mais comuns relatadas nesses pacientes. Ademais, segundo revisão bibliográfica de Galván et al. (2020), algumas das lesões cutâneas foram tratadas com terapias farmacológicas. Em sete pacientes, os anti-histamínicos sistêmicos foram administrados até o desaparecimento das manifestações cutâneas, enquanto em três casos foram prescritos corticosteroides tópicos. Nos outros estudos, nenhum tratamento específico foi realizado e as lesões cutâneas cicatrizaram espontaneamente. Além disso, em 422 pacientes, houve uma recuperação completa sem sequelas; em oito, foi observada uma recuperação parcial, enquanto 12 pacientes morreram antes que as lesões cutâneas cicatrizassem. A duração média dos sintomas cutâneos foi de 7,5 $\pm 3,6$ dias.

Aliado a isso, segundo Bouaziz et al. (2020), os medicamentos usados para o tratamento de pacientes com Covid-19 e manifestações cutâneas foram classificados em três seções: antivirais, antibacterianos e uma combinação de medicamentos, conforme exposto pela Figura 6, sendo o lopinavir e o ritonavir foram os medicamentos antivirais mais amplamente usados (quatro estudos para cada) para o tratamento de pacientes. Entre os medicamentos antibacterianos listados, a azitromicina foi o agente antibacteriano mais amplamente utilizado em seis estudos, e a ceftriaxona e o omeprazol foram outros antibióticos usados em dois estudos para tratar pacientes. Além disso, um regime de tratamento incluindo hidroxicloroquina (HCQ) e azitromicina foi usado em dois estudos e outras terapias foram relatadas apenas em um estudo. Outras combinações de drogas, além de drogas antivirais e antibacterianas, são mostradas na figura como "outras". 
Figura 6: Agentes usados no tratamento de pacientes com Covid-19.

\begin{tabular}{|c|c|c|c|c|}
\hline & Agent & Number of studies & $\mathrm{N} / \mathrm{N}$ & $\%$ \\
\hline \multirow[t]{5}{*}{ Antiveral chug } & Lopenasir & 4 & 4 & 4540.49 \\
\hline & Fitonenir & 4 & 4 & $454(7.4)$ \\
\hline & Osebaminir & 1 & 1 & $1 / 54(1,8)$ \\
\hline & Aencleatie & 2 & 2 & $254.8 .7)$ \\
\hline & Dryctocodsine. & 1 & 1 & 1/54 (1.8) \\
\hline \multirow[t]{11}{*}{ Antboctord this } & Azthrompan & 6. & 6 & $6.54(11.1)$ \\
\hline & Cetpodencrive & 1 & 1 & $1 / 54$ (1.8) \\
\hline & Ceffriaxon & 2 & 2 & $2548 \pi$ \\
\hline & Celcperazone-subtactare & 1 & 1 & VI5 (18) \\
\hline & Omepravicio & 2 & 2 & $2 / 54[3.77$ \\
\hline & Amoxelin-cimudinie acki & 1 & 1 & $1 / 54$ (1.8) \\
\hline & Levoloxacin & 1 & 1 & $1 / 54(1.8)$ \\
\hline & Pperiocilintarobactam & 1 & 1 & $1 / 54$ (1, ह) \\
\hline & Fabeprancle & 1. & 1 & VS4 (1A) \\
\hline & Metocioperanide & 1 & 1 & $1 / 54(1.8)$ \\
\hline & Temaediontidh & 1 & 1 & 1/54 (1. 하) \\
\hline \multirow[t]{6}{*}{ Othen } & Apeemilast & 1 & 1 & $1 / 54(1.8)$ \\
\hline & HCO & 10 & 10 & 1054 (18.5) \\
\hline & Peadhisore & 2 & 2 & $2 / 54(3.7)$ \\
\hline & Pancetamol & 4 & 5 & $5 / 54(2,2)$ \\
\hline & Benzoniatate & 1 & 1 & 1/54 (1. \\
\hline & Hepoin & 1 & 1 & $1 / 54$ (1.8) \\
\hline \multirow{11}{*}{$\begin{array}{l}\text { Combination } \\
\text { therapy }\end{array}$} & Lopinase, Amonave, HCO, Oral predreone & 1 & 1 & $1 / 54(1.8)$ \\
\hline & Asthromych, Benzonatate & 1 & 1 & 1/54 (1. D) \\
\hline & Lopinaver, Atonevis, HCQ Asthroenycin & 1 & 1 & $1 / 54$ (1.8) \\
\hline & 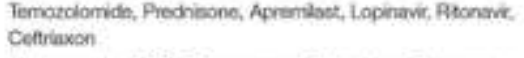 & 1 & 1 & $1 / 54(1.8)$ \\
\hline & Atthromych, HCO Celoperazore Sutustam, Oreprazoin & 1 & 1 & $1 / 54$ (1. 者) \\
\hline & Amoxiclin-Clavianic acid, Heparin & 1 & 1 & V/54 (1.8) \\
\hline & $\mathrm{HOQ}$, activomycin & 2 & 2 & $2 / 54[37]$ \\
\hline & 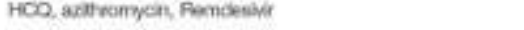 & 1. & 1 & $1 / 54(1.8)$ \\
\hline & Levofoxaon, HCO & 1 & 1 & $1 / 54(1.8)$ \\
\hline & 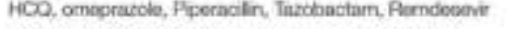 & 1 & 1 & $1 / 54(1.8)$ \\
\hline & 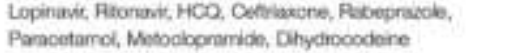 & 1 & 1 & $154(1.8)$ \\
\hline
\end{tabular}

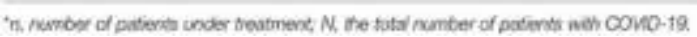

Fonte: Bouaziz et al. (2020).

A análise das manifestações cutâneas nesses estudos, semelhantes aos de estudos de prevalência, mostrou que lesão eritematosa, erupção cutânea e urticária foram as manifestações cutâneas mais comumente relatadas entre pacientes com Covid-19 (Joob et al. 2020). De acordo com pesquisas realizadas nesta área, manifestações cutâneas como exantema tipo varicela, erupção cutânea petéquica, erupção cutânea eritematosa e frieira podem ocorrer nas mãos, pés e tronco, e às vezes podem ser acompanhadas de coceira e até dor (Ehsani et al. 2020). Essas manifestações cutâneas podem estar associadas a sintomas comuns de Covid-19, como febre, tosse seca e mialgia. Portanto, as manifestações cutâneas podem ser consideradas como evidências de variada gama nesses pacientes. Outrossim, Landa et al. (2020) assumem que essas manifestações cutâneas podem ser sintomas secundários de Covid-19, teoria que se baseia no fato de que as manifestações cutâneas aparecem poucas semanas após o pico da infecção.

Além disso, crianças acometidas pela Covid-19 podem apresentar quadro de hiperinflamação, demonstrando alterações nas artérias coronárias, característica da doença de Kawasaki (DK) (Akca et al. 2020), conforme ilustrado pela Figura 7. As crianças apresentam febre alta e persistente, erupções cutâneas, edema nas extremidades, conjuntivite não purulenta, dor abdominal, vômitos e diarreia (Alizargar et al. 2020). Sugere-se que o mecanismo da DK seja baseado em uma reação pós-inflamatória mediada por anticorpos, assim, a identificação da replicação viral não se mostrou verdadeiramente relevante nesses casos (Bailey et al. 2020). Além da ligação da pandemia de Covid-19 e aumento dos casos de DK, outro 
período em que houve pico de incidência da DK foi durante o contexto da pandemia de H1N1, sugerindo que o SARS-CoV-2 não é o único vírus capaz de desencadear tal surgimento da doença de Kawasaki (Figueiredo et al. 2021).

Figura 7: Criança acometida por Doença de Kawasaki.

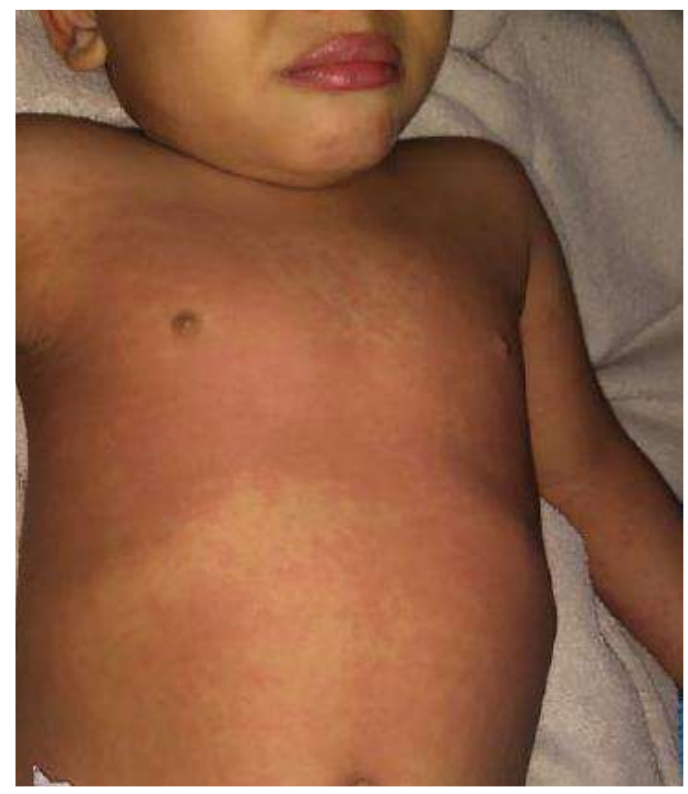

Fonte: Akca et al. (2020).

Apesar da observação de manifestações cutâneas em pacientes com Covid-19, pesquisadores ainda buscam respostas para a questão de saber se essas apresentações cutâneas estão diretamente relacionadas ao próprio vírus ou são complicações da infecção (Colonna et al. 2020). Além disso, em muitos casos, os problemas de pele em pacientes com Covid-19 podem ser devido aos efeitos colaterais dos medicamentos e o vírus pode não ser a causa. Portanto, parece que descobrir a relação potencial entre Covid-19 e as manifestações cutâneas pode auxiliar no melhor entendimento da patogênese da doença e na adoção de melhores políticas de controle de infecção.

Em contraponto, segundo Sameni et al. (2020), alguns pacientes com negatividade do teste Swab poderia ser explicada com o desaparecimento da presença viral detectável após um breve curso assintomático, e, de acordo com esta hipótese, as lesões cutâneas observadas representariam manifestações tardias da infecção por Covid-19 em indivíduos jovens saudáveis, possivelmente devido a uma resposta imunológica direcionada os vasos cutâneos, e a ausência de sinais semelhantes em pacientes acometidos por SARS-CoV-2, de idade avançada, corroboraria esta suposição. Assim, as crianças poderiam ser facilitadoras da transmissão viral na fase inicial, antes do acometimento da pele.

\section{Conclusão}

Desse modo, suspeita-se que essas manifestações cutâneas possam estar relacionadas à Covid-19, haja vista que a relação temporal com a pandemia, o rápido surto e aglomeração de lesões cutâneas incomuns, a ocorrência de casos familiares em uma situação de restrição domiciliar e o relato múltiplo de casos semelhantes de outras áreas afetadas em paralelo com a difusão da pandemia apoiam fortemente isso hipótese. Embora alguns vieses tenham sido encontrados, esta revisão destaca a importância do envolvimento da pele na doença, sendo de suma importância que esses pacientes examinados cuidadosamente para, eventualmente, prever o início de outros sintomas típicos. Além disso, estudos com maior evidência científica são necessários para validar estes achados. 


\section{Referências}

Akca, U. K., Kesici, S., Ozsurekci, Y., Aykan, H. H., Batu, E. D., Atalay, E., Demir, S., Sag, E., Vuralli, D., Bayrakci, B., Bilginer, Y. \& Ozen, S. (2020). Kawasaki-like disease in children with COVID-19. Rheumatology, 40(1), 2105-2115.

Alizargar, J. (2020). The novel coronavirus (COVID-19) and the risk of Kawasaki disease in children. Journal of the Formosan Medical Association, 1-2. https://doi.org/10.1016/j.jfma.2020.05.030

Askin, O., et al. (2020). Manifestações cutâneas em pacientes hospitalizados com diagnóstico de Covid-19. Terapia Dermatológica, 33(6), 1-14.

Avellan, M. R., et al. (2020). Manifestação cutânea de COVID-19 em imagens: relato de caso. J Eur Acad Dermatol Venereol., 34(7), $307-309$.

Bailey, L. C., Razzaghi, H., Burrows, E. K., Bruno, C. \& Forrest, C. B. (2020). Assessment of 135794 Pediatric Patients Tested for Severe Acute Respiratory Syndrome Coronavirus 2 Across the United States. JAMA Pediatrics, 175(2). 176-185.

Bouaziz, J., et al. (2020). Sintomas vasculares cutâneos em COVID-19: um estudo observacional francês. J Eur Acad Dermatol Venereol., 34(8), 451-452.

Colonna, C., et al. (2020). Chilblains-like lesões em crianças após suspeita de infecção por Covid-19. Pediatr Dermatol., 37(3), 437-440.

Ehsani, A. H., et al. (2020). Pitiríase rósea como uma manifestação cutânea de COVID-19 infecção. J Eur Acad Dermatol Venereol., 34 (8), 436 -437.

Figueiredo, B. Q., et al. (2021). Manifestação da Doença de Kawasaki sob espectro clínico da Covid-19: uma revisão sistemática de literatura. Research, Society and Development, 10(11), 1-11. https://doi.org/10.33448/rsd-v10i11.19852

Galván, C. C., et al. (2020). Classificação das manifestações cutâneas de COVID-19: um estudo prospectivo de consenso nacional rápido na Espanha com 375 casos. Br J Dermatol., 4(183), 71-77.

Joob, B., et al. (2020). COVID-19 pode apresentar erupção cutânea e ser confundido com dengue. J Am Acad Dermatol., 82(177), 1-10.

Kaur, I., et al. (2020). Doença por coronavírus (COVID-19): uma revisão atualizada com base no conhecimento atual e na literatura existente para dermatologistas. Dermatol Ther., 33(13677), 60-65.

Landa, N. (2020). Chilblain-like lesões em pés e mãos durante a pandemia COVID-19. Int J Dermatol., 59(7), 739-743.

Marzano, A. V., et al. (2020). Exantema semelhante à varicela como uma manifestação cutânea específica associada à Covid-19: série de casos multicêntricos de 22 pacientes. International Journal of Dermatology, 50(3), 439-444.

Perna, A., et al. (2021). Manifestações cutâneas em pacientes com Covid-19: uma revisão sistemática. International Journal of Dermatology, 60(5), 547-553.

Recalcati, S., et al. (2020). Lesões cutâneas acrais na época de COVID-19. J Eur Acad Dermatol Venereol., 16(3), 1-2.

Sachdeva, M., et al. (2020). Manifestações cutâneas de Covid-19: relato de três casos e revisão de literatura. International Jouurnal of Dermatology, 98(2), 7581 .

Sameni, F., et al. (2020). Covid-19 e manifestações cutâneas: uma visão geral de relatos de caso e mta-análise de estudos de prevalência. Frontiers in Medicina, 7(57), 1-14.

Suchonwanit, P., et al. (2020). Manifestações cutâneas em COVID-19: lições aprendidas de evidências atuais. J Am Acad Dermatol., 83(1), 57-60.

Tammaro, A., et al. (2020). Manifestações cutâneas em COVID-19: as experiências de Barcelona e Roma. J Eur Acad Dermatol Venereol., 34 (7), 306-307.

Tang, K., et al. (2020). Manifestações cutâneas da Doença do Coronavírus 2019 (COVID-19): uma breve revisão . Dermatol Ther., 3(7), 40-50. 